\title{
REPRESENTACIONES DE LA SEXUALIDAD FEMENINA EN LA FICCIÓN DE CHAMOISEAU Y CONFIANT: LA CHABINE Y MAN CHINE
}

\author{
POR \\ JANETH CASAS \\ Universidad de los Andes, Bogotá
}

En este artículo ilustraréla manera como Chamoiseauy Confiant abordan la sexualidad femenina en las Antillas francesas a partir de dos protagonistas cuyo comportamiento es antagónico. Se trata del personaje de una chabine ${ }^{2}$ en la novela Biblique des derniers gestes de Patrick Chamoiseau y del personaje Man Chine en Case à Chine de Raphaël Confiant. Mi objetivo es evidenciar el posicionamiento de los escritores respecto a los valores dominantes en los comportamientos y actitudes sexuales.

En la obra Biblique des derniers gestes, ${ }^{3}$ Chamoiseau lleva al extremo el estereotipo de la chabine como objeto sexual. El nombre de esta chabine es Kalamatia, ${ }^{4}$ nacida del mestizaje amerindio/negro. Paradójicamente, en un primer momento, la sensualidad femenina no es puesta de relieve; el personaje enseña más bien características masculinas: "En un primer acercamiento, no se sabía muy bien si se trataba de un hombre o de una mujer: era una fuerza de la naturaleza, de carácter al parecer terrible [...]" (642). Es por esa razón que, en un principio, Balthazar no demuestra ninguna atracción sexual por ella aunque tuviese algunos rasgos femeninos: "Ella remaba, todos sus músculos potentes se retorcían bajo la tela de su gaule, ${ }^{5}$ una gaule ligera, en tela cruda, que no escondía sus senos desmesurados, ni las boas vigorosas de sus piernas, ni los albores de la piel de su vientre. Esto no perturbaba al joven M. Balthazar Bodule-Jules" (644).

El origen de este personaje pareciera mítico, el lector es llevado a pensar que Kalamatia no es un ser humano. Surgida del mar, es probable que sea una ninfa marina, más específicamente una nereida:

1 Colaboración en la traducción al español de Alejandro Múnevar, Universidad Externado de Colombia.

2 Chabin(e): mestizo(a) de mezclas de color de piel blanco y negro, con predominancia de color claro, cuyos ojos y cabello son generalmente de color claro, siendo este último rizado o crespo.

3 La novela Biblique des derniers gestes será indicada de ahora en adelante Biblique.

4 Chamoiseau describe a Kalamatia como "Una colosal chabine con el cabello color amarillo rojizo, quemado por la sal y por el sol. Tenía una piel rojiza, espesa, con algunos reflejos del color del banano amarillo. [...] Sus ojos eran de un verde botella, sus labios de un rosado azulado casi en un estado de madurez" (642).

5 Gaule: vestido amplio. 
Ella había aparecido sobre la playa, niña pequeña sin palabras, un día que una marea de medusas colonizaba la ensenada. [...] La pequeña chabine [...] les hablaba a las medusas que se fundían en el sol. Una pareja de vieux-corps $s^{6}$ invidentes la recogió sin plantear preguntas y así creció, de manera extraña, sin gusto por el juego, sin nada qué decir, sólo siendo buena para errar por la playa, para jugar en el agua con las medusas y para mirar fijamente el mar como a la espera de una circunstancia particular. (655)

Notemos que, de acuerdo con Jean Chevalier, "[las ninfas] simbolizan la tentación de la locura heroica, que pretende desplegarse mediante proezas de guerra, eróticas o de cualquier orden" (289); el heroísmo y el erotismo constituyen los atributos principales de Kalamatia:

[Él] Veía sus formidables senos batirse como alas. [Él] Veía su kounia ${ }^{7}$ abrirse como un hocico cuando ella saltaba con sus piernas separadas para apuntar a la bestia que estaba emergiendo. [...] Súbitamente, ella saltó hacia lo alto mientras él veía como el monstruo se abalanzaba sobre ella. (Chamoiseau 650)

Esta chabine desafía las prohibiciones de la sociedad en la que vive asumiendo el rol de cazadora y de pescadora, aún sabiendo que eran oficios reservados a los hombres: "Jamás dejaban a una mujer intentarlo. Así como tampoco permitían que una mujer se convirtiese en dueña de cualquier piragua" (Chamoiseau 643). Es importante resaltar que el escritor concibe una sociedad afro-amerindia machista que vive en la autarquía. Por lo tanto, el estereotipo del hombre dominante en materia sexual es ridiculizado y la masculinidad de Balthazar puesta en duda. En otras palabras, Chamoiseau desacredita el machismo tradicional de la sociedad antillana transgrediendo los roles sociales y sexuales de la mujer y del hombre:

Era la primera vez que un cuerpo de mujer lo atrapaba bruscamente como una presa y lo apretaba con una fuerza que superaba la suya. Ofendido, por su parte, trató de apretarla para hacerle entender que una mujer debía comportarse como una mujer. Pero ella quebró sus gestos uno después de otro. Él se encontró en una succión de alguna especie de chatrou $^{8}$ que le aplacaba los riñones, envolvía su espalda, descuartizaba sus muslos, lo dominaba en una ondulación de anaconda voraz. (646)

En esta novela, el autor no restringe ni censura los juegos sexuales de la chabine y Balthazar, en efecto éstos son abordados de manera explícita y lasciva, sin tabúes:

Viejos-cuerpos (vieux-corps): hombre viejo; viejo.

Kounia: Sexo de la mujer.

Chatrou: pulpo. 
$\mathrm{Su} \mathrm{Kal}{ }^{9}$ era absorbido, prensado hasta la muerte y luego enrollado en un envoltura de dulzuras, luego amasado en una serie de contracciones medio eléctricas [...]. Ella lo retomaba con su boca, el tamborileo de sus dedos, lo recubría de una saliva volcánica (con olor a ajo) que lo precipitaba hacia nuevas perdiciones. Ella le afirmaba su kounia sobre su boca, le cubría el rostro con ese cangrejo succionador. (647)

Si consideramos como Freud que los comportamientos instintivos, entre los cuales se encuentra el placer, son reprimidos en el momento en el que interviene la cultura, podemos constatar entonces que ésta constriñe al individuo a rechazar sus pulsiones:

El desarrollo del hombre hasta el momento no me parece que exigiera otra explicación más que la de los animales [...] [El] impulso incansable por perfeccionarse siempre cada vez más, podemos comprenderlo sin problema como la consecuencia de la inhibición pulsional sobre la cual es fundada lo que más tiene valor en la cultura humana. (Essais de psychanalyse 87 )

Teniendo lo anterior en cuenta, Chamoiseau representa las relaciones sexuales al nivel de los instintos, como si tratara de deshacerse de los condicionamientos culturales. Así, concebir el placer desde un punto de vista más primario es una manera de rechazar la cultura impuesta. Es decir, que los personajes de Chamoiseau se despojan de la ambivalencia que Georges Bataille resalta entre lo prohibido e indigno y el placer, resultado éste de la educación: "Humanamente, nunca aparece la prohibición sin la revelación del placer, ni jamás el placer sin el sensación de lo prohibido" (107).

En lo que concierne al cuerpo femenino, Jacqueline Couti sostiene que en las novelas de los creolistas, éste refleja al mismo tiempo un discurso colonial dominante francés y un discurso creol (347). Para las partes íntimas de la mujer y el hombre, la terminología creol es prioritaria; es así que el novelista hace referencia al kal y a la kounia. Es en una práctica creol, pero hiperbólica y sin moderación, que el escritor inscribe la sexualidad, es decir, en relaciones más libertinas y menos constreñidas en cuanto a un pensamiento burgués tradicional. La profusión y la intensidad de la relación sexual entre la chabine y el afroantillano es tal que éste último se ve al borde de la muerte:

[Él] Se desencadenaba, no solamente a causa de las variaciones insensatas del placer, sino también porque se sentía taloneado por la muerte. Quería escaparse, saltar por la borda, pero le volvía el placer, envuelto por una sed de morder, tragar, socavar, golpear y de castigar a quien lo llenaba de un bienestar infinito. (Chamoiseau 649)

Nos encontramos aquí con estas dos pulsiones en simultaneidad-Eros y Thanatos-, aquello sobre lo cual Julia Kristeva insiste: "Pero los dos componentes, que Freud

9 Kal: Verga, pene.

$111 \frac{\text { Revista Iberoamericana, Vol. LXXXII, Núms. 255-256, Abril-Septiembre 2016, 587-593 }}{\text { ISSN 2154-4794 (Electrónico) }}$ 
llamaba Eros y Thanatos, están constantemente en co-presencia" (75). La chabine recibe y da placer pero, al mismo tiempo, ella puede "matar" por placer. En Balthazar, en el umbral del placer y de la muerte, la agresividad emerge bajo la forma de una violencia física como mecanismo de defensa. Según Couti: "la falta de castidad y de retención [...] se oponen a las constricciones sociales burguesas que se remontan al siglo XIX y en las cuales aún está impregnada la cultura martiniqueña contemporánea” (190). Es la razón por la cual, a la par con esta investigadora, percibimos un alcance político al criticar el afrancesamiento de los antillanos en sus comportamientos sexuales: “[...] las travesuras y las imágenes sexuales de los creolistas que se oponen al decoro de la burguesía martiniqueña hambrienta de afrancesamiento sugieren que esta sexualidad es una forma de resistencia subversiva" (192).

Chamoiseau demuestra entonces que a pesar de la imposición de la cultura francesa, en las Antillas existen prácticas sexuales que reflejan la hibridez de su sociedad. Pese a que las narraciones sobre el comportamiento sexual antillano son relatadas sin ningún tipo de juicio de valor negativo, podemos temer al hecho de percibir en el uso de un léxico creol una manera de retomar los estereotipos raciales impuestos por el colonizador, como lo expresa Thomas Spear: "En el texto escrito en francés, podemos en efecto preguntarnos si el vocabulario creol utilizado en las escenas de sexualidad no alienta los estereotipos racistas" (Spear 140).

Cabe resaltar que el escritor aborda la sexualidad sin censurar ni descalificar los términos sexuales y escatológicos:

Era tan fuerte el endulzamiento del placer que se escapaba y se deslizaba hacia el agua, que su piragua atraía una nube de peces de los más raros. Todos venían a probar la salsa del amor. Ese esperma, esos orines, esos sudores, esas materias precipitadas en una melaza fangosa que se alejaba al ritmo de las olas como petróleo derramado en el mar. (Chamoiseau 656)

De esta manera, el escritor adopta un posicionamiento que transgrede igualmente el condicionamiento impuesto por la cultura. Conforme a un enfoque psicoanalítico, Cathérine Garitte afirma lo siguiente: “[En] el estado anal, [...] el niño presenta atracciones condenadas socialmente (amor por la suciedad, interés por los excrementos, agresividad, avaricia, etc.) pero desarrolla al mismo tiempo actitudes contrarias (disgusto, cortesía, generosidad), las actitudes iniciales siendo susceptibles de reaparecerulteriormente"(214).

Está claro que la escatología debe examinarse desde un acercamiento pulsional. En efecto, los personajes llegan a demostrar un placer que se prohíbe a los niños por las normas sociales. Esta premisa, Freud la argumenta a partir de los trabajos de Lou Andreas-Salomé:

El pequeño ser debe en primer lugar tener la intuición [ahnen] de la hostilidad del entorno a sus mociones pulsionales, aprender a distinguir su propio ser de esta entidad

$111 \frac{\text { Revista Iberoamericana, Vol. LXXXII, Núms. 255-256, Abril-Septiembre 2016, 587-593 }}{\text { ISUSN 2154-4794 (Electrónico) }}$ 
extranjera y efectuar enseguida el primer "rechazo" de sus posibilidades de placer. Lo "anal" se presenta a partir de ese momento como el símbolo de todo lo que debe rechazarse, eliminarse de la existencia. (Trois essais 113)

Infringir estas normas puede provocar la risa como lo sustenta Garitte: "teniendo en cuenta que la escatología está colmada de prohibiciones por la educación y la cultura, la transgresión de estas prohibiciones es fuente de risa" (214), es decir que el escritor introduce la burla como un recurso de oposición a la cultura dominante.

En cuanto a la repulsión que el lector pueda experimentar hacia las materias fecales, comportamiento denominado coprofobia, Chamoiseau apela a la apertura del espíritu cuando señala que en las sociedades que practican la coprofilia, la escatología abarca diferentes significaciones, todas positivas. El escritor proporciona un número considerable de informaciones sobre las funciones de las materias fecales en las sociedades de diversos lugares del planeta. ${ }^{10}$ Desde nuestro punto de vista, es significativa la lección moral que el escritor lega al defender el derecho a la diferencia.

Por lo tanto, desvelo dos alcances diferentes en la utilización de la escatología, aquella que hace referencia a la risa y aquella que hace referencia a la ética, como Barbara C. Bowen lo indica para Rabelais: "Lo que para mí importa [es] ver en la escatología de Rabelais lo esencial del método, que consiste en reír y satirizar, o reír y dar una lección moral" (25).

En el caso de Confiant, examino la sexualidad a través de la relación entre Man Chine y el contramaestre Géraud, la cual se augura bajo el signo de la violencia. Al temer la falta de respeto hacia él por tener un comportamiento sentimental a la francesa, el contramaestre afroantillano amenaza con violar a la China, como si estas relaciones prohibidas no pudiesen realizarse más que con la brutalidad: "Señora China, ; he venido a follarte, especie de puta! ¡Me vas a abrir ahora mismo tus caderas de puta o te chuzo como cerdo de navidad!" (208). Esta escena es aun más aberrante ya que una multitud la sigue desde el exterior; pero el escritor no otorga ninguna información sobre lo que sucede al interior. Le corresponde al lector imaginar el desenlace de los eventos que bien podría ser una violación o un acto consentido. Sin embargo, las dos suposiciones son igual de perturbadoras, porque "ningún rastro de arañazo o de sangre indicaba que se hubiese presentado algún tipo de pelea" (209); y "ningún grito de cólera ni estertor de placer emanaron del lugar" (208). Se puede deducir de esta última cita que la cultura de la China, más sosegada y discreta, se impondría al aspecto primario del contramaestre. El novelista desafía los estereotipos ya que concibe una relación entre

\footnotetext{
${ }^{10}$ A título de ejemplo: "[Balthazar] vio, viviendo en la casa de una mujer kabyle, cómo la boñiga de la vaca era la base de catorce encantos mágicos. En un puerto de Inglaterra, vio a su amada mostrarse en el momento muy contenta por recibir heces de ave, y sostener que los sueños sobre el excremento eran un signo de fortuna" (Chamoiseau 657).
}

$111 \frac{\text { Revista Iberoamericana, Vol. LXXXII, Núms. 255-256, Abril-Septiembre 2016, 587-593 }}{\text { ISSN 0034-9631 (Impreso) }}$ 
dos personas que pertenecen a grupos socio-étnicos diferentes y viven su sexualidad sin la violencia que se había previsto. Por otra parte Confiant, a través de la burla, expresa su rechazo contra los prejuicios que el colonialismo forjó con relación a la sexualidad de los afroantillanos: "Man Chin, sé vini koké'w, isalop ki ou yé ! Ou kay wouvè dé katjé manawa'w la ba mwen, osinon man ka anni senyen kotel an kochon Nwel!" [...] (Frase que la moral judeocristiana prohibe traducir) (208).

Otra faceta de las relaciones sexuales es ilustrada mediante una pareja de chinos; aunque son el fruto de un mestizaje, su sexualidad representa un estado de experiencia púdica y mística:

[...] ella me acaricia suavemente el pecho y sonríe. Nuestros cuerpos se enlazan naturalmente, pero nuestras bocas se evitan. Siento lo puntudo de su mentón en la parte hueca de mi hombro, sensación a la vez extraña y deliciosa. Le mordisqueo sus orejas minúsculas. [...] Entro en el Pabellón de la Dulzura Celeste, paso a paso, deteniéndome de vez en cuando, retrocediendo ligeramente en algunos momentos, antes de alcanzar finalmente el palacio de los Placeres Infinitos... (343)

El lector habituado a las novelas de Confiant se muestra por lo menos sorprendido por la retención de sus propósitos teniendo en cuenta que el escritor no escatima generalmente sus esfuerzos para ilustrar la lubricidad de las escenas sexuales mediante el uso de un vocabulario explícito y crudo. Mientras que la salacidad con relación a los otros grupos socio-étnicos es desbordante, en el caso de los chinos está ausente, pues se muestra más en términos de una ternura expresada a través de un léxico metafórico. Confiant establece entonces una diferencia entre los chinos y los afroantillanos al respecto de la manera de asumir el placer y la intimidad sexual:

Las festividades no duraron más que hasta las doce campanadas de la media noche. Las bodas de los chinos no son bodas de negros, había declarado Mei-Wang. Nada de bacanales, de estallidos de voz y de risas, de bailes descaderados y de festines alcoholizados. ¡La vecindad no necesita saber de nuestros asuntos! (343)

Para concluir, cabe resaltar que cada uno de los escritores ilustra a su manera una sociedad multicultural en un espíritu de apertura hacia el Otro e impugna la imposición de un comportamiento sexual acorde con una mentalidad burguesa católica. Sin embargo, si bien Chamoiseau y Confiant se oponen a una manera única de concebir la sexualidad en las Antillas, éstos no logran extraerse de los estereotipos que se le atribuyen a los diferentes grupos socio-étnicos: el afroantillano en su exuberancia sexual y los chinos en su pudor. 


\section{BIBLIOGRAFÍA}

Bataille, Georges. El erotismo. 1957. María Luisa Bastos, trad. Buenos Aires: Editorial Sur, 1960.

Bowen, Barbara. "Rabelais scatologique". Humoresques 22 (2005): 17-27.

Caldwell, Roy Chandler. 'L'Allée des soupirs, ou le grotesque créole de Raphaël Confiant”. Île en île. $<$ http://www.lehman.cuny.edu/ile.en.ile/paroles/confiant_caldwell.html>. 10 julio 2015.

Chamoiseau, Patrick. Biblique des derniers gestes. París: Gallimard, 2002.

Chevalier, Jean. Dictionnaire des symboles. París: Seghers, 1972.

Confiant, Raphaël. Case à Chine. París: Mercure de France, 2007.

Couti, Jacqueline. "Archéologie de la sexualité: recolonisation du corps de la femme noire dans les discours antillais. Tesis de doctorado en filosofía. University of Virginia, 2008.

Freud, Sigmund. Essais de psychanalyse. 1920. París: Payot (Petite Bibliothèque Payot), 1985.

Trois essais sur la théorie sexuelle. 1905. Philippe Koeppel, trad. París: Gallimard, 1987.

Garitte, Catherine. "La scatologie qui fait rire les enfants". Humoresques 22 (2005): 207-222.

Kristeva, Julia. Entre désir et renoncement. París: Éditions Dervy, 1999.

Spear, Thomas. "Jouissances carnavalesques: représentations de la sexualité". Penser la créolité. Maryse Condé y Madeleine Cottenet-Hage, eds. París: Karthala, 1995. 
